\section{Emergence of Sugar Beet Seedlings at Low Soil Temperature following Seed Soaking and Priming}

\author{
Glen Murray ${ }^{1}$ and Jerry B. Swensen ${ }^{2}$ \\ Department of Plant, Soil and Entomological Sciences, University of Idaho, \\ Moscow, ID 83843-4196
}

\section{John J. Gallian ${ }^{3}$}

Department of Plant, Soil and Entomological Sciences, University of Idaho, P.O. Box 1827, Twin Falls, ID 83303-1827

Additional index words. Beta vulgaris, germination, seed preconditioning, seed washing

Abstract. Seedling emergence from primed and nonprimed sugar beet seed (Beta vulgaris L.) was studied for 3 years under field conditions near Kimberly, Idaho, and compared with germination or emergence under controlled laboratory conditions. Maximum seedling emergence did not vary with seed treatment in spite of low field soil temperatures. Time to $50 \%$ of maximum emergence was significantly less for seed primed with polyethylene glycol 8000 than for nonprimed seed in only 1 of 3 years. Seed soaked in 30C water for 24 $h$ performed similarly to nontreated seed in the field, but their maximum emergence was significantly improved compared with primed seed in one of two laboratory experiments. Time to $50 \%$ of maximum germination was improved by priming with or without a warm water soak in one of the two laboratory experiments.

Rapid, uniform seedling emergence of early planted sugar beet, which is closely related to the red table beet (Beta vulgaris L.), enhances the probability of high yields. However, low soil temperature during early seeding in Idaho and other sugar beet production areas often delays seedling emergence and increases the probability of soil crusting and seedling disease. Problems with postemergence weed control and thinning may arise later because of

Received for publication 23 Mar. 1992. Accepted for publication 10 Sept. 1992. Approved for publication as Idaho Agriculture Experiment Station no. 89727. This research was partially funded by the Nyssa-Nampa Beet Growers Assn. We thank the Amalgamated Sugar Co. for supplying seed, and Del Traveller for assistance in conducting field experiments. The cost of publishing this paper was defrayed in part by the payment of page charges. Under postal regulations, this paper therefore must be hereby marked advertisement solely to indicate this fact.

'Professor.

${ }^{2}$ Research Associate.

${ }^{3}$ Associate Professor. uneven plant size and stands. Priming table beet seed with polyethylene glycol (PEG) has improved seedling emergence in cold soils, thus reducing the aforementioned problems (Khan et al., 1983).

Priming seeds in PEG involves incubating them in an aerated solution (Heydecker and Coolbear, 1977). Water potential of the priming solution and priming temperature and duration are selected to prevent radicle elongation but to allow most other germination processes. After priming, seeds are rinsed, dried, and planted.

Compared with nontreated seed, table beet seed primed with PEG reached $50 \%$ of final germination nearly 10 days sooner, and $200 \%$ more seedlings emerged in the field 20 days after planting (Khan et al., 1983). Taylor et al. (1985) found that pythium incidence was less on table beet seedlings from PEG-primed seed than from nontreated seed. Murray et al. (1987) and W.R. Akeson (unpublished data) have shown enhanced sugar beet seedling performance from PEG-primed seed.

The cortical tissue of sugar beet and table beet seed contains germination inhibitors (Mitchell and Tolbert, 1968). Removing these inhibitors by washing seed in water enhanced table beet germination and emergence compared with unwashed table beet seed (Khan et al., 1983).

Our study was undertaken to determine the influence of PEG priming and water soaking on sugar beet seedling emergence under field conditions in southern Idaho. Seedling performance in the field from treated and nontreated seed was compared with seedling performance under controlled laboratory conditions.

Seed and preplanting treatments. Monogerm seed of 'WS-76' sugar beet (Amalgamated Sugar Co., Twin Falls, Idaho) planted each year was harvested the previous year and processed commercially to give seeddiameters of 3.2 to $3.6 \mathrm{~mm}$.

Thirty grams of seed were suspended by a cheesecloth bag in 2.8-liter flasks containing 2 liters of PEG 8000 and held at 15C. The solution was aerated vigorously throughout the treatment by passing 1.5 to 2.0 liters of air/ min through a bubble stone at the bottom of each flask. The priming solution concentration was maintained at $302 \mathrm{~g}$ PEG/liter of water by adding distilled water twice daily to the original solution volume. From Michel's equation no. 1 , solution water potential was calculated as -1.22 mPa (Michel, 1983). Priming solutions contained $0.2 \mathrm{~g}$ tetramethylthiuram disulfide (thiram)/liter to control fungal growth. Thiram was not used in any other treatment or the control. Continuous light was supplied by $40-\mathrm{W}$ cool-white fluorescent lamps at $13 \mu \mathrm{mol} \cdot \mathrm{m}^{-2} \cdot \mathrm{s}^{-1}$ measured at seed height.

Primed seed was rinsed in running distilled water to remove PEG, blotted to surface dryness, spread in a single layer on dry towels, and dried for $24 \mathrm{~h}$ in an air stream at 20C. Final seed weights were $\approx 1 \%$ less than initial seed weight due to leaching and loss of fines through the cheesecloth bag.

To remove potential chemical inhibitors and improve subsequent priming and germination, a separate $60 \mathrm{~g}$ seedsample was placed in a cheesecloth bag and suspended in 2 liters of water at 30C. Water and seed were aerated vigorously for $24 \mathrm{~h}$ as described above. Seeds were removed, placed on paper towels, and dried for $24 \mathrm{~h}$ in an air stream at 20C. After washing and drying, one-half of the washed seed was osmoconditioned for 7 days at $15 \mathrm{C}$ as described above. 
Field trials. Seeds were hand-planted at the Research and Extension Center, Univ. of Idaho, Kimberly, on 16, 10, and 21 Apr. 1985, 1986, and 1987, respectively. Sixty seeds of each treatment were planted $1.9 \mathrm{~cm}$ deep and $10.2 \mathrm{~cm}$ apart in 9.1-m-long rows with $0.56 \mathrm{~m}$ between rows. Seedling emergence from the entire row length was recorded daily, starting with initial emergence and continuing until either emergence ceased or some plant loss occurred.

Seedling emergence was evaluated by maximum percentage of emerged seedlings, and the time needed to reach $50 \%\left(\mathrm{~T}_{50}\right)$ of this maximum value. The highest emergence was considered maximum, while $\mathrm{T}_{50}$ was calculated by linear interpolation between the two emergence observations that bracketed the $T_{50}$ value. This calculation was performed for each experimental unit. Within each year, $\mathrm{T}_{50}$ and maximum emergence variances were analyzed separately. Means were separated using a protected LSD at $P=0.05$.

No significant differences in maximum emergence were detected among seed treatments in any of the three field studies. Maximum emergence was $67 \%$ to $79 \%, 47 \%$ to $50 \%$, and $84 \%$ to $90 \%$ in 1985,1986 , and 1987, respectively. Soil temperatures, which were especially low in 1986, resulted in unusually low emergence, while warmer and drier than normal soil temperatures in 1987 resulted in unusually high emergence. The average soil temperature at a 5-cm depth for sugar beet planted between 1 and 30 Apr. was $11 \mathrm{C}$, with 10 days below 11C.

Lack of maximum emergence response to priming when soils were cold contrasts with data presented by Khan et al. (1983). Soil temperatures in our study, compared to those reported by Khan, were similar in 1985 but much lower in 1986. In 1986, the soil temperature at $5 \mathrm{~cm}$, from planting through maximum emergence, was $\leq 11 \mathrm{C}$ for 18 of 29 days. In Khan's study, average soil temperature at $5 \mathrm{~cm}$ during the same period was $\leq 11 \mathrm{C}$ for only 9 of 35 days in 1980 and 7 of 36 days in 1982. These data suggest that, while priming improved emergence at soil temperatures below optimum (Khan et al., 1983), it may be less effective at improving emergence when soil temperature is near the minimum required for germination. In the absence of low temperature and other stresses in 1987 (no days <11C), priming was not expected to enhance maximum emergence.

$\mathrm{T}_{50}$ varied significantly in response to seed treatments only in the 1987 study (Table 1). In this year, the $T_{50}$ values of osmotically primed sugar beet seeds, with or without a water soak, were $\approx 0.5$ days shorter than those of nontreated seeds or seeds receiving only a water soak. Durrant and Payne (1983) showed that priming with inorganic salts improved sugar beet seedling emergence under moisture stress similar to our 1987 study.

Controlled-environment trials. In 1986 and 1987, seeds were treated as previously described for field trials. After treatment in 1986, 10 seeds were planted in pots containing sand packed to a bulk density of $\approx 1.4 \mathrm{~g} \cdot \mathrm{cm}^{-3}$ (Akeson and Widner, 1980) and placed in growth chambers at $10 \mathrm{C}$. Water content of the sand was $4 \%$ by weight. In 1987, 100 seeds were placed on moistened blotters in covered petri dishes and germinated at 24C. Emergence in 1986 and germination in 1987 were scored daily until germination and emergence, respectively, remained constant for three consecutive days. A randomized complete block design with four replications was used in both studies and data were analyzed as previously described.

An additional treatment was included in both field and laboratory emergence tests in 1986, and in the 1985 field test. Gibberellic acid was added to primed seed using the method of Akeson et al. (1981). This treatment improved neither maximum emergence nor $T_{50}$ compared with primed seed in any of these experiments and was not included in the 1987 experiments.

Seedling emergence from preconditioned seed planted in packed sand (Akeson and Widner, 1980) in 1986 did not follow the same pattern as field emergence from seed that received the same preconditioning treatments (Table 1). Maximum emergence was highest from seed that was soaked in water for $24 \mathrm{~h}$ at $30 \mathrm{C}$. This treatment resulted in significantly better maximum emergence than priming with or without soaking in the packed sand test. No treatment improved maximum emergence compared with emergence from nontreated

Table 1. Influence of preconditioning on maximum emergence and time to $50 \%$ of maximum emergence $\left(T_{50}\right)$ of 'WS-76' sugar beet seedlings at Kimberly, Idaho, during three crop years (a) and under controlled laboratory conditions (b).

\begin{tabular}{|c|c|c|c|c|c|c|c|}
\hline \multirow{3}{*}{$\begin{array}{l}\text { Preconditioning } \\
\text { treatment }\end{array}$} & \multicolumn{2}{|c|}{$\begin{array}{l}\text { Max emergence or } \\
\text { germination }(\%)^{z}\end{array}$} & \multicolumn{5}{|c|}{$\mathrm{T}_{50}$ (days) } \\
\hline & 1986 & 1987 & \multirow{2}{*}{$\frac{1985}{\text { a only }}$} & \multicolumn{2}{|c|}{1986} & \multicolumn{2}{|c|}{1987} \\
\hline & \multicolumn{2}{|c|}{ (b only) } & & a & b & a & $\mathrm{b}$ \\
\hline Control & 53 & 93 & 10.5 & 16.8 & 22.6 & 9.8 & 2.4 \\
\hline Water soak & 73 & 95 & 10.2 & 16.7 & 22.1 & 9.9 & 2.4 \\
\hline PEG alone & 43 & 92 & 9.6 & 16.5 & 24.4 & 9.5 & 2.0 \\
\hline Water + PEG & 28 & 93 & 10.5 & 17.0 & 24.6 & 9.4 & 1.7 \\
\hline $\operatorname{LSD}(0.05)$ & 24 & NS & NS & NS & NS & 0.3 & 0.2 \\
\hline
\end{tabular}

${ }^{2}$ The 1986 emergence test was conducted in packed sand at $10 \mathrm{C}$, while the 1987 germination test was done on blotters in petri dishes at $24 \mathrm{C}$.

${ }^{\text {s } N o n s i g n i f i c a n t ~ a t ~} P=0.05$.

seed. $\mathrm{T}_{5_{0}}$ values did not vary significantly among treatments in this test. Seedling response to preconditioning treatments in the packed sand test, therefore, could not be used to predict field performance in 1986 even though soil temperature was low in both cases.

In 1987, the maximum germination percentage patterns and $T_{50}$ values of seed in petri dishes were both similar to maximum emergence and $\mathrm{T}_{50}$ responses observed in the field (Table 1). Priming seed with PEG or washing it for $2 \mathrm{~h}$ at $30 \mathrm{C}$ and then priming with PEG improved germination rate in petri dishes and emergence rate in the field. Germination responses in petri dishes, therefore, could have been used to predict emergence responses from preconditioned seed under the warmer 1987 conditions. However, as anticipated, maximum germination of treated and nontreated seed under laboratory conditions was higher, and $\mathrm{T}_{50}$ values lower, than emergence in the field.

Considering both 1986 and 1987 laboratory and field data, seedling response to preconditioning treatments depends on the environment and, perhaps, seed lot. In the absence of disease and other stress, priming with PEG did not improve maximum field emergence of sugar beets agronomically and only slightly improved emergence rate in one of three field experiments. Effectiveness of priming sugar beet and, possibly, table beet seed may diminish as temperature approaches the minimum required for germination.

\section{Literature Cited}

Akeson, W.R., A.H. Freytag, and M.A. Henson. 1981. Improvement of sugarbeet seed emergence with dilute acid and growth regulator treatments. Crop Sci. 21:307-312.

Akeson, W.R. and J.N. Widner. 1980. Laboratory packed sand test for measuring vigor of sugar beet seed. Crop Sci. 20:641-644.

Durrant, M.J. and P.A. Payne. 1983. The use of water and some inorganic salt solutions to advance sugarbeet seed. II. Experiments under controlled and field conditions. Ann. Appl. Biol. 103:517-526.

Heydecker, W. and P. Coolbear. 1977. Seed treatments for improved performance-Survey and attempted prognosis. Seed Sci. \& Technol. 5:353425.

Khan, A.A., N.H. Peck, A.G. Taylor, and C. Samimy. 1983. Osmoconditioning of beet seeds to improve emergence and yield in cold soil. Agron. J. 75:788-794

Michel, B.E. 1983. Evaluation of the waterpotential of solutions of polyethylene glycol 8000 both in the absence and presence of other solutes. Plant Physiol. 72:66-70.

Mitchell, E.D., Jr., and N.E. Tolbert. 1968. Isolation from sugarbeet fruit and characterization of cis4-cylcohexene-1,2-dicarboximide as a germination inhibitor. Biochemistry 7:1019-1025.

Murray, G.A., J.J. Gallian, M.A. Kay, and K. Stewart. 1987. Seedling emergence from preconditioned sugarbeet seed. Univ. of Idaho Winter Commodity Schools 19:213-216.

Taylor, A.G., Y. Hadar, J.M. Norton, A.A. Khan, and G.E. Harman. 1985. Influence of presowing seed treatments of tablebeets on the susceptibility of damping off caused by Pythium. J. Amer. Soc. Hort. Sci. 110(4):516-519. 